160

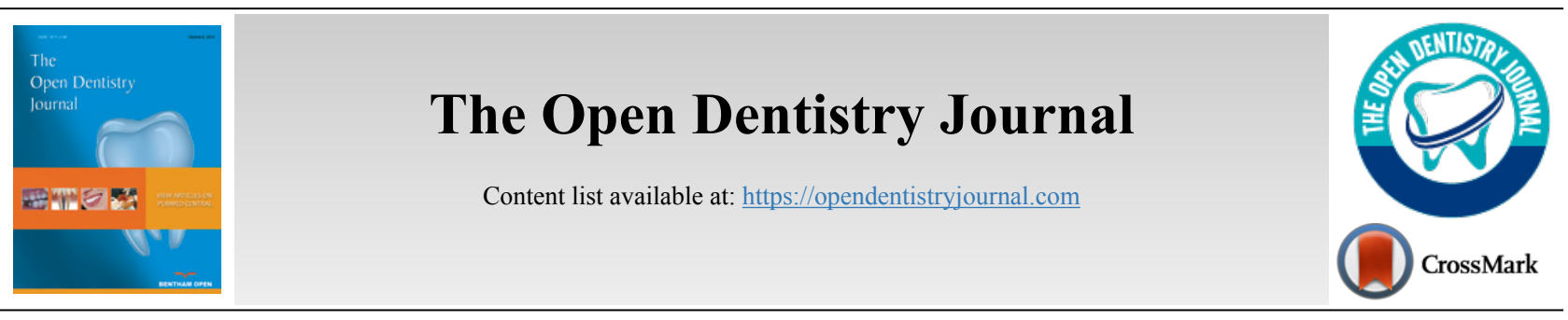

RESEARCH ARTICLE

\title{
Awareness and Utilization of Bulk-Fill Composites among Dental Practitioners in Saudi Arabia
}

\author{
Hani M. Nassar ${ }^{1, *}$ and Ensanya A. Abou Neel ${ }^{2,3,4}$ \\ ${ }^{I}$ Department of Restorative Dentistry, Faculty of Dentistry, King Abdulaziz University, Jeddah, Saudi Arabia \\ ${ }^{2}$ Preventive and Restorative Dentistry Department, Collegeof Dental Medicine, University of Sharjah, Sharjah, United Arab Emirates \\ ${ }^{3}$ Biomaterials Department, Faculty of Dentistry, Tanta University, Tanta, Egypt \\ ${ }^{4}$ University College London, Eastman Dental Institute, Biomaterials and Tissue Engineering Division, London, United Kingdom
}

\begin{abstract}
:
Objective:

The aim of this study was to assess the knowledge and utilization of Bulk-Fill (BF) resin composites among dental practitioners in Saudi Arabia.

Materials and Methods:

An online survey was distributed through Twitter, Instagram and WhatsApp applications among dentists in Saudi Arabia. A 31-item questionnaire covering personal data, general knowledge and utilization of BF composites was used. Responses were collected and analyzed for trends. A knowledge scale was developed based on answers with specific weight for each correct answer provided by the participants. A score of $\geq 50 \%$ was considered as a satisfactory knowledge level for participants. Statistical analysis was conducted using One-sample Z- and Chi-square tests followed by Bonferroni correction at 0.05 significance level.

\section{Results:}

The total number of participants of the survey was 183 , of which $41.5 \%$ had some knowledge and utilized BF composites in their practice. Only $9.84 \%$ of the participants score $\geq 50 \%$ on the knowledge scale. A significantly low proportion recognized accurately the compositional difference between BF and conventional resin composite as well as the minimum irradiance values needed for proper polymerization of BF. There was no effect for gender or years of experience on the knowledge or utilization of BF materials $(p$-value $=0.172)$.

\section{Conclusion:}

The proportions of practitioners with adequate knowledge and utilization of BF materials were very low. Additional focus must be provided in order to expose graduating dentists to advances in resin composite formulations.
\end{abstract}

Keywords: Bulk-fill, Composite, Knowledge, Utilization, Dental practitioners, Awareness.

\begin{tabular}{l|l|l|l} 
Article History & Received: November 28, 2020 & Revised: January 27, 2021 & Accepted: February 15, 2021
\end{tabular}

\section{INTRODUCTION}

The use of dental composite is increasing owing to patient's demand for tooth-colored restorations [1]. The properties of composite resins have improved significantly in the last few years [2]; however, inherent limitation owing to the shallow depth of cure of resin composite necessitated the utilization of an incremental technique during the placement of

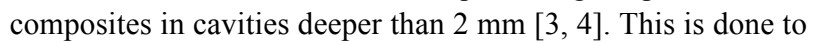
ensure that light from curing devices can reach the deeper parts

\footnotetext{
Address correspondence to this author at the Department of Restorative Dentistry, Faculty of Dentistry, King Abdulaziz University, Jeddah, Saudi Arabia; Tel: +96612695000; E-mail: hnassar@kau.edu.sa
}

of the restoration leading to an adequate degree of conversion of monomers into polymers [5]. This is very critical to the longevity of the restorations since it was reported previously that under-cured resin composites are more likely to fail, necessitating their replacement [6 - 8].

In order to streamline the clinical procedure of deeper cavities, new formulations were developed which allow for the filling of cavities up to $5 \mathrm{~mm}$ deep in a single increment. These materials are known as Bulk-Fill (BF) resin composites [9]; and have different chemistries compared to conventional resin composites [10]. BF materials tend to have special fillers with more translucency values in order to allow deeper penetration 
of light [11]. Also, higher light-cure irradiance values are required in order to deliver enough energy into the bottom of the cavity enabling the polymerization of the material. Even though, irradiance values between 400 and $600 \mathrm{~mW} / \mathrm{cm}^{2}$ can be considered adequate for curing conventional resin composite [12], BF formulations require irradiance values exceeding $1,000 \mathrm{~mW} / \mathrm{cm}^{2}$ in order to ensure an adequate degree of conversion [13]. Further, new and more sensitive photoinitiators are used to ensure adequate initiation and propagation of the polymerization reaction [9].

Understanding key differences in chemistry and application techniques between conventional and BF resin composite is very important to clinicians. Since these materials are relatively new, not all practicing dentists might be aware of these differences. Choosing the correct material, the proper application technique and the light curing device with adequate irradiance value are paramount in ensuring a successful restoration. Furthermore, proper utilization data must be known in order to provide relevant recommendations for daily practice, especially for recently graduating dentists.

Thus, the aim of the current study was to assess the knowledge and utilization of dental practitioners of bulk-fill resin composite materials. Establishing a baseline knowledge status can allow decision-makers and university professors to cope with workplace practices as well as community demand.

\section{MATERIALS AND METHODS}

\subsection{Ethics Statement}

The questionnaire and methodology for this study were approved by the Research Ethics Committee of the Faculty of Dentistry at King Abdulaziz University (Ethics approval number: 112-10-19 in April, $\left.3^{\text {rd }}, 2019\right)$. Further, a confidentiality disclosure was included in the introductory portion of the online questionnaire. The study was conducted between November 2019 and March 2020.

\subsection{Target Group}

The target audience for the survey was dental practitioners in Saudi Arabia. The questionnaire was sent electronically via social media applications (Twitter, Instagram, Telegram, and Whatsapp) based on local databases targeting governmental universities and hospitals as well as private schools and practices. The selection was random based on sending the link over the social media outlets.

\subsection{Online Questionnaire Design}

The online questionnaire was designed using Google Forms software (Google LLC, Mountain View, California, United States) and was divided into sections: 1) demographic data [8 questions], 2) knowledge about BF resin composite properties and technique [16 questions], and 3) utilization of $\mathrm{BF}$ resin composite in daily practice [6 questions]. After the demographic information part of the survey, two conditional questions were included in the survey at the beginning of the knowledge and utilization sections (Fig. 1). Based on answering these two questions, the participants were categorized into 3 groups: 1) participants without knowledge, 2) participants with knowledge but no utilization, or 3) participants with knowledge and utilization.

\subsection{Study Parameters}

For each parameter within the demographic data, each answer level was compared to others to determine trends and differences within the sample. For each question within the knowledge section, the proportion of participants with the correct answer was determined. Each correct answer was given a score, and the total knowledge scale (KS; out of 25 points) was determined for each participant to estimate the level of knowledge concerning BF resin composite. A KS $\geq 50 \%$ was considered a satisfactory knowledge level. For the utilization section, proportions of answers for each question were compared. Furthermore, the effect of demographic data on knowledge and the effect of knowledge on utilization were also investigated.

\subsection{Statistical Analysis}

All Data were collected, tabulated and subjected to statistical analysis. All analyses were performed using SPSS Version 20 (SPSS Inc., Chicago, Illinois, USA). Qualitative categorical variables were described by frequencies and percentages. Data were presented, when appropriate, by the Pareto method. Quantitative variables were described by the mean and standard deviation.

Shapiro-Wilk test of normality was used to test the normality hypothesis of the knowledge scale. $Z$ test was applied for the difference between two proportions. Chisquared test was used for the assessment of the relation between two categorical variables. Post-hoc analysis using adjusted residuals and Bonferroni correction were used for further analysis of the effect of employment status if the chisquared test was significant. A 0.05 significance level was used for all tests. During analysis, some answer options were grouped together in order to maintain the statistical assumptions of the test.

\section{RESULTS}

\subsection{Demographic Data}

A total of 195 responses were received for the online survey; of which 12 were excluded (10 participants were interns and 2 responses had missing data; Fig. 1). Consequently, the final number of participants in this survey was 183 practitioners. Fifty-one participants did not have previous knowledge of $\mathrm{BF}$ composites, and 132 had some knowledge; of which 76 practitioners had used BF composite at some point. The general characteristics of the cohort are included in Table 1. Most participants were general practitioners (95\%), graduated from King Abdulaziz University $(57 \%)$ during the last 10 years $(91 \%)$, and with less than 5 years of experience $(86 \%)$. 


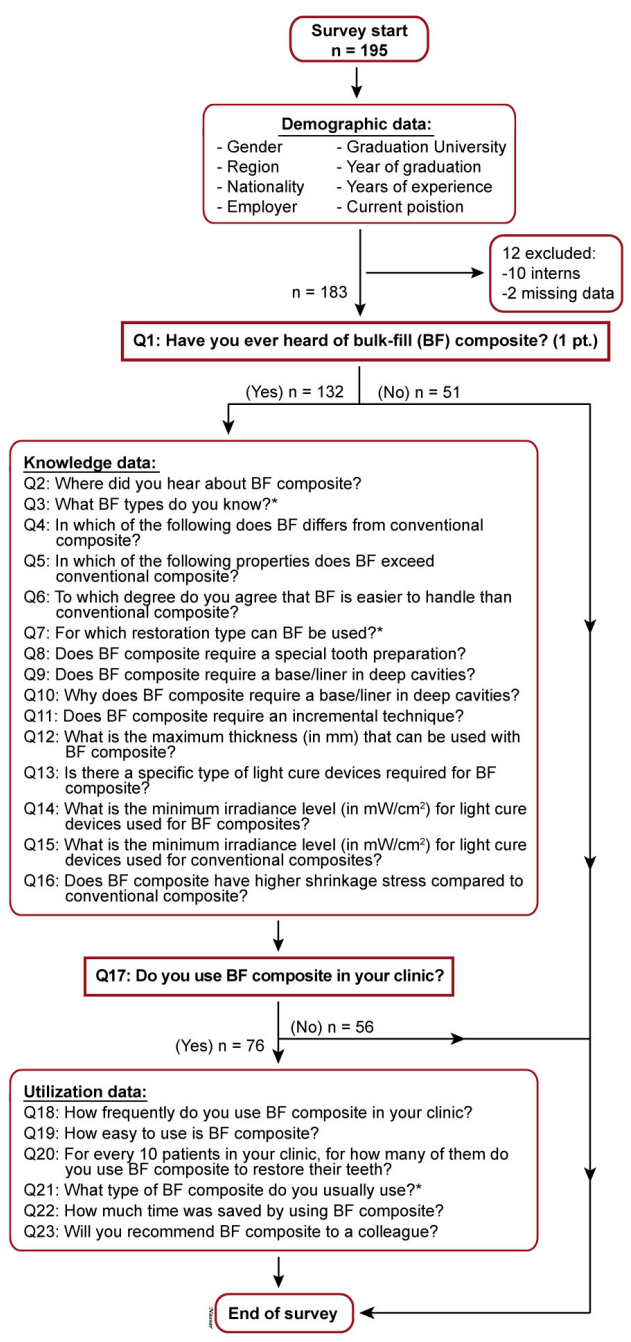

Fig. (1). A flowchart showing the different questions of the survey and number of participants at each stage depending on the answers for the conditional questions (outlined with rectangles). Questions 1 and 17 were conditional inquiries which were used to categorize participants according to their knowledge and utilization of $\mathrm{BF}$ resin composites. Asterisks indicate questions with multiple answers; the rest of the questions were in multiple choice format.

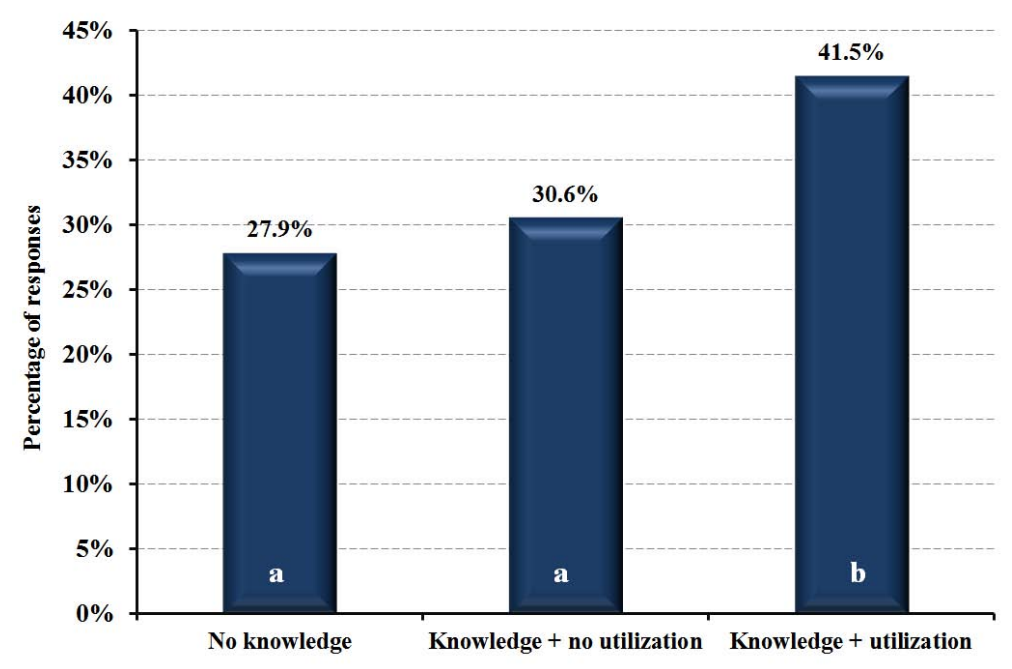

Fig. (2). A bar graph showing overall proportions of participants regarding knowledge and utilization. Different letters indicate significant differences $(p \leq 0.05)$. Overall, only $9.84 \%$ of the participants $(n=183)$ had satisfactory knowledge regarding bulk-fill composites (scoring $\geq 50 \%$ on the used knowledge score). 
Table 1. Summary of demographic data. Asterisks indicate statistically higher response compared to other options within the same question $(p \leq 0.05)$.

\begin{tabular}{|c|c|c|c|c|}
\hline Category & Response & Percent & Significance Between Responses & P-Value for Z-test \\
\hline Gender & Male & 49.7 & \multirow{2}{*}{ No } & \multirow{2}{*}{0.92} \\
\hline & Female & 50.3 & & \\
\hline \multirow[t]{2}{*}{ Nationality } & Saudi* & 97.8 & \multirow{2}{*}{ Yes } & \multirow{2}{*}{$<0.001$} \\
\hline & Non-Saudi & 2.2 & & \\
\hline \multirow[t]{5}{*}{ City/region } & Central region & 9.8 & \multirow{5}{*}{ Yes } & \multirow{5}{*}{$<0.001$} \\
\hline & Western region* & 80.9 & & \\
\hline & Eastern region & 4.9 & & \\
\hline & Northern region & 1.1 & & \\
\hline & Southern region & 3.3 & & \\
\hline \multirow[t]{10}{*}{ Graduation University } & Taiba University & 3.8 & \multirow{10}{*}{ Yes } & \multirow{10}{*}{$<0.001$} \\
\hline & King Saud University & 4.4 & & \\
\hline & King Khalid University & 1.6 & & \\
\hline & Um Al Qura University & 2.2 & & \\
\hline & Alfarabi College & 4.4 & & \\
\hline & King Abdulaziz University* & 57.4 & & \\
\hline & Ibn Sina College & 9.8 & & \\
\hline & Batterjee College & 2.7 & & \\
\hline & Imam University & 1.6 & & \\
\hline & Other & 12 & & \\
\hline \multirow[t]{5}{*}{ Year of Graduation } & Before 1980 & 0 & \multirow{5}{*}{ Yes } & \multirow{5}{*}{$<0.001$} \\
\hline & $1981-1990$ & 0.6 & & \\
\hline & $1991-2000$ & 2.7 & & \\
\hline & $2001-2010$ & 6.0 & & \\
\hline & $2011-2019 *$ & 90.7 & & \\
\hline \multirow[t]{4}{*}{ Current Position } & General practitioner* & 94.5 & \multirow{4}{*}{ Yes } & \multirow{4}{*}{$<0.001$} \\
\hline & Specialist & 3.8 & & \\
\hline & Consultant & 1.1 & & \\
\hline & Other & 0.6 & & \\
\hline \multirow[t]{4}{*}{ Years of Experience } & $<5^{*}$ & 86.3 & \multirow{4}{*}{ Yes } & \multirow{4}{*}{$<0.001$} \\
\hline & $5-9$ & 10.9 & & \\
\hline & $10-15$ & 1.1 & & \\
\hline & $>15$ & 1.1 & & \\
\hline \multirow[t]{3}{*}{ Employer } & Unemployed & 44.8 & \multirow{3}{*}{ No } & \multirow{3}{*}{0.054} \\
\hline & Government & 31.7 & & \\
\hline & Private & 23.5 & & \\
\hline
\end{tabular}

\subsection{Knowledge Data}

Only 76 out of $183(41.5 \%)$ participants have the knowledge and utilize BF composite. Fig. (2) illustrates the proportions of participants in regards to knowledge and utilization. There was no significant difference between females (18\%) and males (9.9\%) regarding knowledge of BF materials $(p=0.172)$. The knowledge scale $(\mathrm{KS})$, normalized on a 100 point, with a score below $50 \%$ was considered unsatisfactory. The KS data followed a normal distribution and showed that only 18 out of $123(9.84 \%)$ participants had a satisfactory knowledge level. KS was not influenced by gender, years of experience or employment status $(p>0.05)$.

Table $\mathbf{2}$ shows the proportions of answers for each question in the knowledge section of the survey along with the results of statistical tests. The data is presented both out of the total participants of the survey $(n=183$; percentages might not add to $100 \%$ ) and out of the participants who responded yes to Q1 $(\mathrm{n}=132$; percentages will add up to $100 \%)$. Lectures were the main source of information (Fig. 3), SDR was the most commonly reported BF material by participants, and core build-up was the most frequent application reported (Fig. 4).

Considering the difference between BF and conventional composites, only a significantly low proportion (7\%) chose "photoinitiators" $(p<0.001)$. A similarly low proportion $(7 \%)$ chose "degree of conversion/depth of cure" $(p<0.001)$. In addition, $\mathrm{BF}$ materials were considered easier to use compared to conventional formulations $(p<0.001)$, being not suitable for anterior restorations $(6 \%)$, and do not require a special cavity preparation $(62 \%)$ or an incremental approach $(70 \%)$. 
Regarding the minimum irradiance level in $\mathrm{mW} / \mathrm{cm}^{2}$ for light cure used for BF resin composites, 300 - 600, 601 - 900, and $901-1200 \mathrm{~mW} / \mathrm{cm}^{2}$ were the ranges commonly chosen with no statistical significance between the choices. ( $p>0.05$;
Fig. 5). For conventional composites, however, 901 - 1200, 300 - 600, and 601 - 900 were the ranges chosen with no statistically significant difference between the choices $(p>$ $0.05)$.

Table 2. Statistical comparisons for each question of the knowledge section of the survey according to answers.

\begin{tabular}{|c|c|c|c|c|c|c|c|c|}
\hline \multirow[t]{2}{*}{ Question } & \multirow[t]{2}{*}{ Answer (Abbreviation) } & \multicolumn{2}{|c|}{$\begin{array}{l}\text { Out of Total } \\
\text { Participants } \\
\quad(n=183)^{1}\end{array}$} & \multicolumn{2}{|c|}{$\begin{array}{l}\text { Percentage out of } \\
\text { Knowledgeable } \\
\text { Participants } \\
(\mathrm{n}=132)^{2}\end{array}$} & \multirow[t]{2}{*}{ Multiple Comparison } & \multirow[t]{2}{*}{$P$-Value } & \multirow[t]{2}{*}{$\begin{array}{c}\text { Knowledge } \\
\text { Score (points) }\end{array}$} \\
\hline & & $\%$ & Total & $\%$ & Total & & & \\
\hline Q2 & Lectures (L) & 31 & 69 & 44 & 100 & L vs. S & 0.043 & 1 \\
\hline- & Supervisors (S) & 21 & & 31 & - & S vs. W & 0.007 & 1 \\
\hline- & Workshops (W) & 11 & - & 16 & - & W vs. C & 0.091 & 1 \\
\hline- & Conferences (C) & 6 & - & 9 & - & & & 1 \\
\hline Q3 & SDR (BF1) & 35 & 105 & 33 & 100 & BF1 vs. BF2 & 0.58 & 0.5 \\
\hline- & FilltekBulk-Fill (BF2) & 32 & & 31 & - & BF1 vs. BF3 & 0.022 & 0.5 \\
\hline- & TetricBulk-Fill (BF3) & 24 & & 23 & - & $\mathrm{BF} 2$ vs. $\mathrm{BF} 3$ & 0.081 & 0.5 \\
\hline- & Sonic Fill 2 (BF4) & 14 & & 13 & - & $\mathrm{BF} 2$ vs. BF4 & $<0.001$ & 0.5 \\
\hline- & & & & - & - & BF3 vs. BF4 & 0.011 & \\
\hline Q4 & Polymers (P) & 11 & 106 & 11 & 100 & Ph vs. P) & $<0.001$ & 0 \\
\hline- & Filler particles (FP) & 27 & & 26 & - & Ph vs. FP & $<0.001$ & 0 \\
\hline- & Photoinitiators $(\mathrm{Ph})$ & 8 & & 7 & - & & & 2 \\
\hline- & Polymerization reaction $(\mathrm{PR})$ & 19 & & 18 & - & Ph vs. PR & $<0.001$ & 0 \\
\hline- & $\begin{array}{l}\text { Polymerization shrinkage and gap } \\
\text { formation (PS) }\end{array}$ & 40 & - & 38 & - & Ph vs. PS & $<0.001$ & 0 \\
\hline Q5 & Durability (D) & 17 & 126 & 13 & 100 & DC vs. D & $<0.001$ & 0 \\
\hline- & Color stability (CS) & 9 & & 7 & - & DC vs. CS & $<0.001$ & 0 \\
\hline- & Polymetric stability (PS) & 18 & & 14 & - & DC vs. PS & $<0.001$ & 0 \\
\hline- & Marginal adaptability (MA) & 28 & & 22 & - & DC vs. MA & $<0.001$ & 0 \\
\hline- & Degree of conversion/depth of cure (DC) & 8 & - & 7 & - & - & - & 2 \\
\hline- & Polymerization shrinkage (PS) & 44 & & 35 & - & DC vs. PS & $<0.001$ & 0 \\
\hline- & None & 2 & & 1 & - & DC vs. None & $<0.001$ & 0 \\
\hline- & Other & & & 1 & - & DC vs. Other & $<0.001$ & 0 \\
\hline Q6 & Agree vs. strongly agree & 56 & 68 & 78 & 100 & Agree vs. Disagree & $<0.001$ & $0.5 / 1.0$ \\
\hline- & Disagree vs. strongly disagree & 6 & & 8 & - & & & 0 \\
\hline- & Undecided & 6 & & 14 & - & & & 0 \\
\hline Q7 & Core Buildup (TR1) & 49 & 131 & 38 & 100 & TR1 vs. TR2 & 0.015 & 0.5 \\
\hline- & Posterior Restoration (TR2) & 37 & & 28 & - & TR2 vs. TR3 & 0.662 & 1 \\
\hline- & MOD (TR3) & 34 & & 26 & - & TR2 vs. TR4 & $<0.001$ & 1 \\
\hline- & Anterior Restoration (TR4) & 6 & & 5 & - & TR3 vs. TR4 & $<0.001$ & 0 \\
\hline- & I don't know & 4 & & 3 & - & & & 0 \\
\hline Q8 & No & 44 & 72 & 62 & 100 & No vs. Yes & $<0.001$ & 1 \\
\hline- & Yes & 9 & & 13 & - & & & 0 \\
\hline- & Maybe & 10 & & 14 & - & & & 0 \\
\hline- & I don't know & 8 & & 11 & - & & & 0 \\
\hline Q9 & No & 14 & 72 & 19 & 100 & No vs. Yes & $<0.001$ & 0 \\
\hline- & Yes & 44 & & 61 & - & & & 1 \\
\hline- & I don't know & 14 & & 20 & - & & & 0 \\
\hline Q10 & $\begin{array}{l}\text { For pulpal protection from unreacted } \\
\text { monomer (BDC1) }\end{array}$ & 27 & 72 & 38 & 100 & $\mathrm{BDC} 1$ vs. $\mathrm{BDC} 2$ & 0.276 & 1 \\
\hline- & $\begin{array}{l}\text { For pulpal protection from mechanical } \\
\text { irritant (BDC2) }\end{array}$ & 22 & & 31 & - & $\mathrm{BDC} 1$ vs. $\mathrm{BDC} 3$ & $<0.001$ & 0 \\
\hline- & For better marginal adaptation (BDC3) & 5 & - & 7 & - & BDC2 vs. BDC3 & $<0.001$ & 0 \\
\hline- & I don't know & 17 & & - & - & & & 0 \\
\hline Q11 & No & 50 & 72 & 70 & 100 & No vs. Yes & $<0.001$ & 0.5 \\
\hline
\end{tabular}




\begin{tabular}{|c|c|c|c|c|c|c|c|c|}
\hline \multirow[t]{2}{*}{ Question } & Answer (Abbreviation) & \multicolumn{2}{|c|}{$\begin{array}{l}\text { Out of Total } \\
\text { Participants } \\
\quad(n=183)^{1}\end{array}$} & \multicolumn{2}{|c|}{$\begin{array}{l}\text { Percentage out of } \\
\text { Knowledgeable } \\
\text { Participants } \\
(n=132)^{2}\end{array}$} & \multirow[t]{2}{*}{ Multiple Comparison } & \multirow[t]{2}{*}{$P$-Value } & \multirow{2}{*}{\begin{tabular}{|c}
$\begin{array}{c}\text { Knowledge } \\
\text { Score (points) }\end{array}$ \\
0 \\
\end{tabular}} \\
\hline & Yes & 9 & & 12 & - & & & \\
\hline- & Maybe & 8 & & 11 & - & & & 0 \\
\hline- & I don't know & 5 & & 7 & - & & & 0 \\
\hline Q12 & 3 & 13 & 72 & 18 & 100 & 3 vs. 4 & $<0.001$ & 0 \\
\hline- & 4 & 34 & & 47 & - & $\geq 5$ vs. 4 & 0.067 & 2 \\
\hline- & $\geq 5$ & 25 & & 35 & - & $\geq 5$ vs. 3 & 0.009 & 0 \\
\hline Q13 & No & 54 & 72 & 74 & 100 & No vs. Yes & $<0.001$ & 0 \\
\hline- & Yes & 19 & & 26 & - & & & 2 \\
\hline Q14 & $300-600$ (IRR1) & 23 & 72 & 32 & 100 & IRR1 vs. IRR2 & 0.303 & 0 \\
\hline- & $601-900$ (IRR2) & 19 & & 26 & - & IRR1 vs. IRR3 & 0.115 & 0 \\
\hline- & $901-1,200$ (IRR3) & 16 & & 23 & - & IRR1 vs. IRR4 & $<0.001$ & 2 \\
\hline- & $>1,200$ (IRR4) & 8 & & 11 & - & IRR2 vs. IRR3 & 0.582 & 0 \\
\hline- & $<300$ (IRR5) & 6 & & 8 & - & IRR2 vs. IRR4 & 0.004 & 0 \\
\hline- & & & & - & - & IRR3 vs. IRR4 & 0.017 & \\
\hline- & & & & - & - & IRR4 vs. IRR5 & 0.416 & \\
\hline Q15 & $901-1,200($ IRR1) & 24 & 72 & 33 & 100 & IRR1 vs. IRR2 & 0.452 & 0 \\
\hline- & 300 - 600 (IRR2) & 21 & & 29 & - & IRR1 vs. IRR3 & 0.092 & 1 \\
\hline- & $601-900$ (IRR3) & 17 & & 24 & - & IRR1 vs. IRR4 & $<0.001$ & 2 \\
\hline- & $<300$ (IRR4) & 8 & & 11 & - & IRR2 vs. IRR3 & 0.35 & 0 \\
\hline- & $>1,200$ (IRR5) & 2 & & 3 & - & IRR2 vs. IRR4 & 0.001 & 0 \\
\hline- & & & & - & - & IRR3 vs. IRR4 & 0.012 & \\
\hline- & & & & - & - & IRR4 vs. IRR5 & 0.01 & \\
\hline Q16 & No & 20 & 72 & 28 & 100 & No vs. Yes & 0.068 & 2 \\
\hline- & Yes & 28 & & 39 & - & & & 0 \\
\hline- & Maybe & 10 & & 14 & - & & & 0 \\
\hline- & I don't know & 14 & & 19 & - & & & 0 \\
\hline
\end{tabular}

${ }^{\mathrm{I}}$ Percentages out of the total survey participants. Percentages might not add up to $100 \%$

${ }^{2}$ Percentages out of participants who responded yes to Q1 (participants with knowledge about bulk-fill composites). Percentages will add up to $100 \%$.

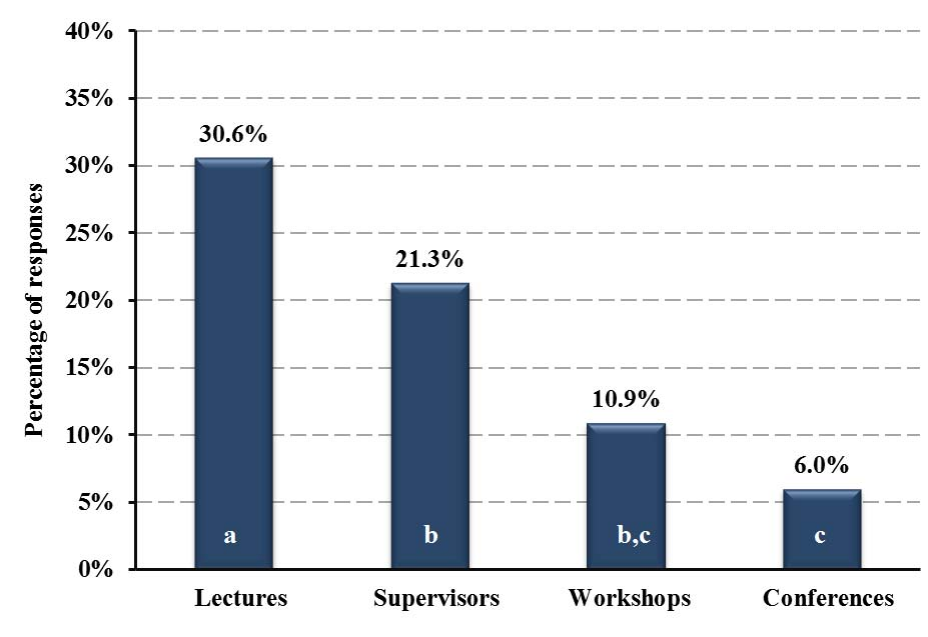

Methods for obtaining infomration about bulk-fill resin composites

Fig. (3). A bar graph showing data for sources mentioned by the participants for information regarding bulk-fill materials. Different letters indicate significant differences $(p \leq 0.05)$. 


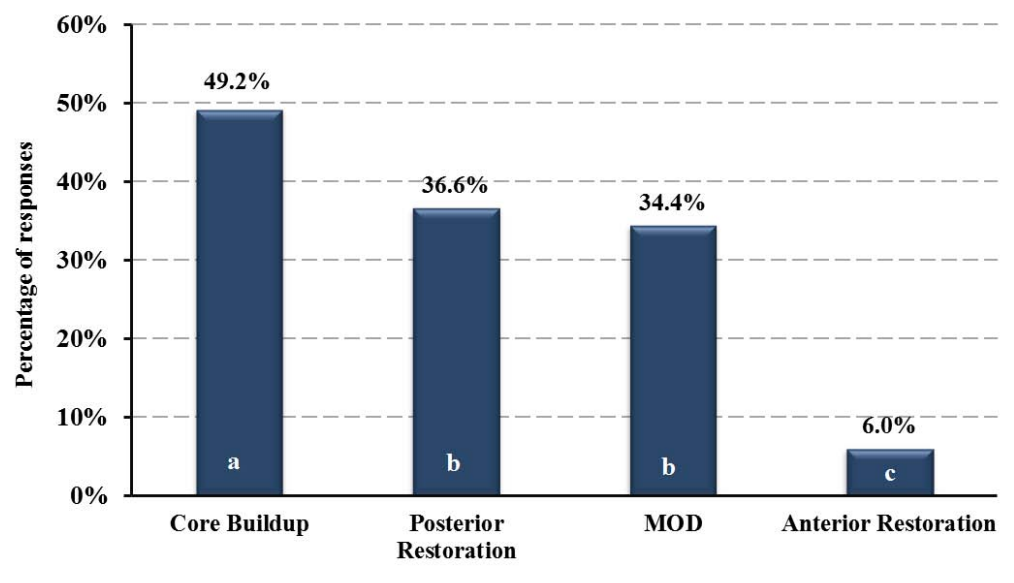

Applications of bulk-fill resin composite materials

Fig. (4). A bar graph showing data for applications mentioned by the participants for bulk-fill materials. Different letters indicate significant differences $(p \leq 0.05)$.

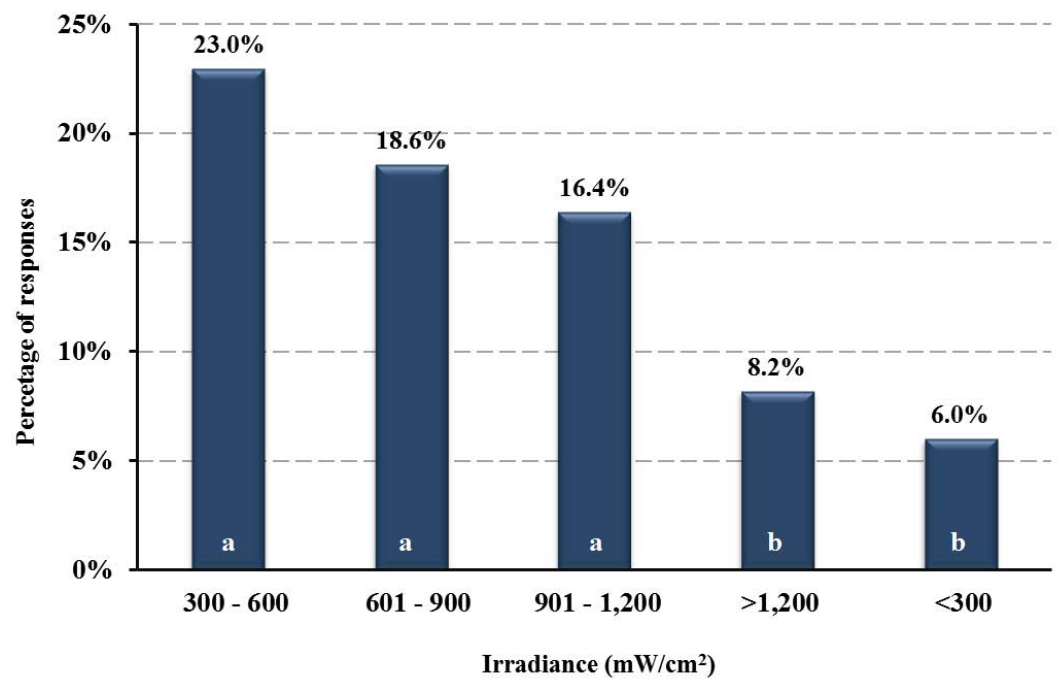

Fig. (5). A bar graph showing data for minimum irradiance levels mentioned by the participants for bulk-fill materials. Different letters indicate significant differences $(p \leq 0.05)$.

Table 3. Statistical comparisons for each question of the utilization section of the survey according to answers.

\begin{tabular}{|c|c|c|c|c|c|c|c|}
\hline \multirow[t]{2}{*}{ Question } & \multirow[t]{2}{*}{ Answer (Abbreviation) } & \multicolumn{2}{|c|}{$\begin{array}{l}\text { Out of Total Participants } \\
(\mathrm{n}=\mathbf{1 8 3})^{1}\end{array}$} & \multicolumn{2}{|c|}{\begin{tabular}{|c|} 
Percentage out of Bulk Fill Users \\
$(\mathrm{n}=76)^{2}$
\end{tabular}} & \multirow[t]{2}{*}{ Multiple Comparison } & \multirow[t]{2}{*}{$P$-Value } \\
\hline & & $\%$ & Total & $\%$ & Total & & \\
\hline \multirow[t]{4}{*}{ Q18 } & Never & 31 & 72 & 42 & 100 & Never vs. Rarely & 0.076 \\
\hline & Rarely & 22 & - & 31 & - & Never vs. Often & $<0.001$ \\
\hline & Sometimes (every 2-3 month) & 7 & - & 9 & - & Rarely vs. Often & 0.013 \\
\hline & Often & 13 & - & 18 & - & Sometimes vs. Often & 0.051 \\
\hline \multirow[t]{2}{*}{ Q19 } & Easy & 27 & 40 & 68 & 100 & Easy vs. Other responses & $<0.001$ \\
\hline & Other responses (not easy) & 13 & - & 32 & - & - & - \\
\hline \multirow[t]{2}{*}{ Q20 } & $1-3$ & 29 & 42 & 70 & 100 & $1-3$ vs. 4 or more & $<0.001$ \\
\hline & 4 or more & 13 & - & 30 & - & - & - \\
\hline \multirow[t]{4}{*}{ Q21 } & SDR (BF1) & 23 & 56 & 41 & 100 & BF1 vs. BF2 & 0.369 \\
\hline & Filltek Bulk-Fill(BF2) & 19 & - & 34 & - & BF1 vs. BF3 & 0.002 \\
\hline & Tetric Bulk-Fill (BF3) & 11 & - & 20 & - & BF2 vs. BF3 & 0.028 \\
\hline & SonicFill 2 (BF4) & 2 & - & 4 & - & BF3 vs. BF4 & $<0.001$ \\
\hline
\end{tabular}




\begin{tabular}{|c|c|c|c|c|c|c|c|}
\hline \multirow[t]{2}{*}{ Question } & \multirow{2}{*}{$\begin{array}{c}\text { Answer (Abbreviation) } \\
\text { Other }\end{array}$} & \multicolumn{2}{|c|}{$\begin{array}{l}\text { Out of Total Participants } \\
(\mathrm{n}=\mathbf{1 8 3})^{1}\end{array}$} & \multicolumn{2}{|c|}{$\begin{array}{c}\begin{array}{c}\text { Percentage out of Bulk Fill Users } \\
(\mathrm{n}=76)^{2}\end{array} \\
\end{array}$} & \multirow{2}{*}{$\begin{array}{c}\text { Multiple Comparison } \\
-\end{array}$} & \multirow{2}{*}{\begin{tabular}{|c|}
$P$-Value \\
- \\
\end{tabular}} \\
\hline & & 1 & - & 1 & - & & \\
\hline \multirow[t]{3}{*}{ Q22 } & Very little & 8 & 39 & 20 & 100 & A lot of time vs. Very little & 0.01 \\
\hline & Sometime & 15 & - & 38 & - & A lot of time vs. Sometime & 0.665 \\
\hline & A lot of time & 16 & - & 42 & - & Sometime vs. Very little & 0.031 \\
\hline \multirow[t]{2}{*}{ Q23 } & No/Maybe & 10 & 42 & 24 & 100 & No/Maybe vs. Yes & $<0.001$ \\
\hline & Yes & 32 & - & 76 & - & - & - \\
\hline
\end{tabular}

${ }^{1}$ Percentages out of the total survey participants. Percentages might not add up to $100 \%$.

${ }^{2}$ Percentages out of participants who responded yes to Q17 (bulk-fill user).Percentages will add up to $100 \%$.

\subsection{Utilization Data}

There was no significant effect for years of experience on the utilization of BF materials. Also, the effect of gender was not significant (females $=49.2 \%$, males $=36.6 \% ; p=0.172$ ). However, Post-hoc analysis with Bonferroni correction revealed that unemployed participants had lower utilization compared to the employed groups $(p=0.017)$.

Table 3 summarizes answers for each question in the utilization section of the survey as well as results of statistical analysis. The data is presented both out of the total participants of the survey $(n=183$; percentages might not add to $100 \%)$ and out of the participants who responded yes to Q17 $(\mathrm{n}=76$; percentages will add up to $100 \%$ ). The majority of participants did not use BF resin composites (53\%); however, among those who did, SDR was the most used $(23 \%)$, and $27 \%$ of these groups considered the technique to be easy. Still, only between 1 and 3 in every 10 patients are provided a BF composite restoration since only $31 \%$ of the group utilizing $\mathrm{BF}$ believed it saved them sometime during the clinical encounter.

Regardless of the ease of use and time saving with $\mathrm{BF}$ composites, these factors have no statistically significant effect on the use or frequency of use of BF composites ( $p>0.05$ ). However, there was a strong correlation between the ease of use and recommendation of the use of BF composites to a colleague $(p<0.001)$.

\section{DISCUSSION}

BF composites have been launched to the dental market to simplify restorative procedures by filling cavities in one increment. This has been related to the translucency of resin matrix [14] and the development of new photoinitiator systems [15], which allow curing of BF composites in an increment of 4 $-5 \mathrm{~mm}$ [16]. Since then, their use has been extended to cover several applications, including posterior restorations [17], bases and liners [18] and core build-up [19]. These materials are available as low viscous (flowable) or highly viscous (sculptable). The flowable types suit deep parts of cavities as they can easily flow to fill all parts, but they are not strong enough to withstand forces of mastication. They, therefore, have to be capped with the more viscous type [20]. This survey aimed to investigate the awareness and utilization of $\mathrm{BF}$ composites among dental practitioners working in Saudi Arabia.

The proportion of females with satisfactory knowledge level was higher than males, but when it comes to utilization, females had a lower utilization rate than males. As expected, with $\geq 5$ years of experience, the level of satisfactory knowledge and utilization of BF composites increases and working in privates sectors was associated with a higher level of satisfactory knowledge and utilization rate. On the contrary, regardless of the ease of use and time saving with $\mathrm{BF}$ composites as highlighted by participants, this has no impact on their utilization or frequency of use but the recommendation to colleagues. This indicates that there is no association between the knowledge the participants had and their utilization. This could be related to materials availability, participants' preference, or lack of training.

Considering the difference between BF and conventional composites, polymerization shrinkage and gap formation came first but not photoinitiators, degree of conversion, and depth of cure. This could indicate that the participants are only concerned with the clinical performance of the material but not with the actual change in composition that brought such performance. Several approaches have been employed by manufacturers to improve the depth of cure of BF composites [21]. They include the addition of more reactive photoinitiators to the commonly used comphorquinone [22]. Another approach relies on increasing the material translucency by increasing the filler content, reducing the filler size and controlling its refractive index [23]. It is imperative that the practicing dentist becomes aware of these variations in order to modify the application technique based on the intended application.

Regarding the polymerization shrinkage and gap formation of $\mathrm{BF}$ versus conventional composites, there is a big controversy in the literature, and this has always been related to the type of BF being used [24, 25, 23]. Some studies showed that $\mathrm{BF}$ composite has lower polymerization shrinkage and gap formation than conventional composites [26, 27]. Other studies, however, showed comparable shrinkage for both material types [28, 29]. Studies focusing on photoinitiator systems in both $\mathrm{BF}$ and conventional composites are very scarce. This might also contribute to the lack of concern of participants with the type of photoinitiators in their responses.

Although participants showed good overall knowledge regarding the fact that bulk-fill composites can be used at once to fill cavities of $4-5 \mathrm{~mm}$, it should also be brought to attention that in cases where the cavity depth is greater than 5 $\mathrm{mm}$, as in endodontically treated teeth or in class II cavities with very deep gingival margin, an incremental approach is recommended with a maximum incremental size of $4-5 \mathrm{~mm}$ following manufacturer's recommendations. This is needed to 
ensure adequate transfer of the light energy from the light cure device across the material and into the deeper potions of the filling.

Polymerization of the dental composite is crucial for optimizing its physical and mechanical properties as well as the clinical success [30]. Inadequate polymerization results in reduced mechanical and physical properties, decreased bond strength with tooth structure, marginal deterioration, and possible cytotoxicity [31]. Therefore, using the appropriate light-curing unit to deliver adequate and sufficient energy required for optimum polymerization is needed. For polymerization of dental composites, irradiation with blue or blue/violet light is required [32]. Parameters as irradiance, radiance exposure, and irradiation spectrum are the main parameters to be considered for each light curing unit used for polymerization of dental composites [32]. With recent light emitting diode (LED) curing devices, the irradiance has been dramatically enhanced to reduce the exposure time required for successful polymerization [33]. Most modern devices operate at irradiance of $1000-1500 \mathrm{~mW} / \mathrm{cm}^{2}$. The conventional quartztungesten-halogen $(\mathrm{QTH})$ curing devices have irradiance level of $400-500 \mathrm{~mW} / \mathrm{cm}^{2}$, [34]. With BF composites that have a variety of photoinitiators, the development of curing unit with multiple LEDs (polywave LED) has been introduced to emit different wavelengths to cover different photoinitiators [36]. For most BF composites, a monowave or polywave LED curing device with irradiance level $\geq 1000 \mathrm{~mW} / \mathrm{cm}^{2}$ is required [35]. From the responses in the survey, there is a knowledge gap regarding the minimum irradiance level required for both $\mathrm{BF}$ and conventional composites. The most commonly chosen level was $300-600 \mathrm{~mW} / \mathrm{cm}^{2}$ for BF and $901-1200 \mathrm{~mW} / \mathrm{cm}^{2}$ for conventional composites.

\section{CONCLUSION}

According to the results of this survey, several key points require reinforcement and hands-on training in both didactic and clinical sessions. Firstly, nearly $93 \%$ of the participants, unemployed males with $>5$ years of experience, in particular, have unsatisfactory knowledge level about BF composites. Since the study was conducted between November 2019 and March 2020, some effects of the COVID-19 pandemic might have affected the employment status. Secondly, most participants considered polymerization shrinkage and gap formation, but not the photoinitiator and depth of cure, as the main difference between $\mathrm{BF}$ and conventional composites. Thirdly, the minimum irradiance level of light cure, required for $\mathrm{BF}$ and conventional composites, has also been misperceived by participants. Finally, regardless of the ease of use and time saving with BF composites as highlighted by participants, these factors had no statistically significant effect on the use or frequency of use of $\mathrm{BF}$ composites by participants. The highest utilization rate was observed with those having $\geq 5$ years of experience; still, the overall utilization of BF was low. There was, however, a strong correlation between the ease of use and recommendation of the use of BF composites to colleagues. Therefore, for a future course or program improvement, different ways to encourage participants to apply what they learn should be considered to solve this issue.

\section{ETHICS APPROVAL AND CONSENT TO PARTICIPATE}

This study was approved by the ethical committee of the Ethics Committee of the Faculty of Dentistry at King Abdulaziz University, Saudi Arabia (Ethics approval number: 112-10-19 in April, $\left.3^{\text {rd }}, 2019\right)$.

\section{HUMAN AND ANIMAL RIGHTS}

No animals were used in this research. All human research procedures followed were in accordance with the ethical standards of the committee responsible for human experimentation (institutional and national), and with the Helsinki Declaration of 1975, as revised in 2013.

\section{CONSENT FOR PUBLICATION}

A consent form was signed by all participants.

\section{AVAILABILITY OF DATA AND MATERIALS}

The data that support the findings of this study are available from the corresponding author, [H.M.N.] upon a reasonable request.

\section{FUNDING}

None.

\section{CONFLICT OF INTEREST}

The authors declare no conflict of interest, financial or otherwise.

\section{ACKNOWLEDGEMENTS}

Declared none.

\section{REFERENCES}

[1] Van Ende A, De Munck J, Lise DP, Van Meerbeek B. Bulk-Fill composites: A review of the current literature. J Adhes Dent 2017; 19(2): 95-109.

[PMID: 28443833]

[2] Poggio C, Lombardini M, Gaviati S, Chiesa M. Evaluation of Vickers hardness and depth of cure of six composite resins photo-activated with different polymerization modes. J Conserv Dent 2012; 15(3): 237-41.

[http://dx.doi.org/10.4103/0972-0707.97946] [PMID: 22876009]

[3] Rees JS, Jagger DC, Williams DR, Brown G, Duguid W. A reappraisal of the incremental packing technique for light cured composite resins. J Oral Rehabil 2004; 31(1): 81-4.

[http://dx.doi.org/10.1046/j.0305-182X.2003.01073.x] [PMID: 15125602]

[4] Soares CJ, Rodrigues MP, Oliveira LRS, et al. An evaluation of the light output from 22 contemporary light curing units. Braz Dent J 2017; 28(3): 362-71.

[http://dx.doi.org/10.1590/0103-6440201601466] [PMID: 29297558]

[5] Son SA, Park JK, Jung KH, Ko CC, Jeong CM, Kwon YH. Effect of $457 \mathrm{~nm}$ diode-pumped solid state laser on the polymerization composite resins: Microhardness, cross-link density, and polymerization shrinkage. Photomed Laser Surg 2015; 33(1): 3-8. [http://dx.doi.org/10.1089/pho.2014.3786] [PMID: 25549163]

[6] Rueggeberg FA, Caughman WF, Curtis JW Jr. Effect of light intensity and exposure duration on cure of resin composite. Oper Dent 1994; 19(1): 26-32.

[PMID: 8183730 ]

[7] Tjan AH, Bergh BH, Lidner C. Effect of various incremental 
techniques on the marginal adaptation of class II composite resin restorations. J Prosthet Dent 1992; 67(1): 62-6.

[http://dx.doi.org/10.1016/0022-3913(92)90051-B] [PMID: 1548611]

[8] Jadhav S, Hegde V, Aher G, Fajandar N. Influence of light curing units on failure of directcomposite restorations. J Conserv Dent 2011; 14(3): 225-7.

[http://dx.doi.org/10.4103/0972-0707.85793] [PMID: 22025822]

[9] Menees TS, Lin CP, Kojic DD, Burgess JO, Lawson NC. Depth of cure of bulk fill composites with monowave and polywave curing lights. Am J Dent 2015; 28(6): 357-61.

[PMID: 26897758]

[10] El-Damanhoury H, Platt J. Polymerization shrinkage stress kinetics and related properties of bulk-fill resin composites. Oper Dent 2014; 39(4): 374-82

[http://dx.doi.org/10.2341/13-017-L] [PMID: 23865582]

[11] Kim EH, Jung KH, Son SA, Hur B, Kwon YH, Park JK. Effect of resin thickness on the microhardness and optical properties of bulk-fill resin composites. Restor Dent Endod 2015; 40(2): 128-35. [http://dx.doi.org/10.5395/rde.2015.40.2.128] [PMID: 25984474]

[12] Bansal RHB, Kumar A, Bansal M, Gupta C, Singla S. Are we doing justice? A clinical survey of the output intensity of light curing units in dental offices. Indian J Dent Sci 2012; 4: 9-11.

[13] AlQahtani MQ, Michaud PL, Sullivan B, Labrie D, AlShaafi MM, Price RB. Effect of high irradiance on depth of cure of a conventional and a bulk fill resin-based composite. Oper Dent 2015; 40(6): 662-72. [http://dx.doi.org/10.2341/14-244-L] [PMID: 26237638]

[14] Lassila LV, Nagas E, Vallittu PK, Garoushi S. Translucency of flowable bulk-filling composites of various thicknesses. Chin J Dent Res 2012; 15(1): 31-5. [PMID: 22866280]

[15] Santos A, Proença L, Polido M, Cristina Azul A. Depth of cure of bulk-fill light cured composite resins with different initiators. Annals of Medicine 2019; 51(sup1): 141.

[http://dx.doi.org/10.1080/07853890.2018.1561985]

[16] Pereira R, Giorgi MCC, Lins RBE, et al. Physical and photoelastic properties of bulk-fill and conventional composites. Clin Cosmet Investig Dent 2018; 10: 287-96.

[http://dx.doi.org/10.2147/CCIDE.S184660] [PMID: 30588124]

[17] Manhart J, Hickel R. Bulk-fill-composites. Modern application technique of direct composites for posterior teeth. Swiss Dent J 2014; 124(1): 19-37.

[PMID: 24665478]

[18] Alothman S, Ansari S. Survival of direct posterior composite with and without a bulk fill base. Asian J Sci Technol 2018; 08(12): 7229-33.

[19] Warangkulkasemkit S, Pumpaluk P. Comparison of physical properties of three commercial composite core build-up materials. Dent Mater J 2019; 38(2): 177-81.

[http://dx.doi.org/10.4012/dmj.2018-038] [PMID: 30381634]

[20] Ruchi Gupta AKT. Anamika Kumari, Saurabh Mullick and, Dubey S. Bulkfill flowable composite resins: A review. Int J Applied Dent Sci 2017; 3(2): 38-40.

[21] Bahbishi N, Mzain W, Badeeb B, Nassar HM. Color stability and micro-Hardness of bulk-Fill composite materials after exposure to common beverages. Materials (Basel) 2020; 13(3)E787 [http://dx.doi.org/10.3390/ma13030787] [PMID: 32050415]

[22] Monterubbianesi R, Orsini G, Tosi G, et al. Spectroscopic and mechanical properties of a new generation of bulk fill composites.
Front Physiol 2016; 7: 652.

[http://dx.doi.org/10.3389/fphys.2016.00652] [PMID: 28082918]

[23] Mahmood AM. Comparison Depth of cure of different viscosities bulk fill composite materials. Int J Sci Res (Ahmedabad) 2017; 6(5): 2201-3.

[24] Benetti AR, Havndrup-Pedersen C, Honoré D, Pedersen MK, Pallesen U. Bulk-fill resin composites: polymerization contraction, depth of cure, and gap formation. Oper Dent 2015; 40(2): 190-200. [http://dx.doi.org/10.2341/13-324-L] [PMID: 25216940]

[25] Ersen KA, Gürbüz Ö, Özcan M. Evaluation of polymerization shrinkage of bulk-fill resin composites using microcomputed tomography. Clin Oral Investig 2020; 24(5): 1687-93. [http://dx.doi.org/10.1007/s00784-019-03025-5] [PMID: 31346784]

[26] Hakan Kamalak AK. Evaluation of polymerization shrinkage of dental composites by microcomputed tomography. Biomed Res (Aligarh) 2018; 29(4): 844-52.

[27] Sampaio CS, Fernández Arias J, Atria PJ, et al. Volumetric polymerization shrinkage and its comparison to internal adaptation in bulk fill and conventional composites: A $\mu \mathrm{CT}$ and OCT in vitro analysis. Dent Mater 2019; 35(11): 1568-75.

[http://dx.doi.org/10.1016/j.dental.2019.07.025] [PMID: 31500903]

[28] Jang J-H, Park S-H, Hwang I-N. Polymerization shrinkage and depth of cure of bulk-fill resin composites and highly filled flowable resin. Oper Dent 2015; 40(2): 172-80

[http://dx.doi.org/10.2341/13-307-L] [PMID: 25136904]

[29] Najla A. Eltoum NSB, Dalia M. Talaat, Sonia M. Elshabrawy. Microleakage evaluation of bulk-fill composite in class II restorations of primary molars. Alexandria Dent J 2019; 44: 111-6. [http://dx.doi.org/10.21608/adjalexu.2019.57614]

[30] Galvão MR, Caldas SG, Bagnato VS, de Souza Rastelli AN, de Andrade MF. Evaluation of degree of conversion and hardness of dental composites photo-activated with different light guide tips. Eur J Dent 2013; 7(1): 86-93. [PMID: 23407620]

[31] Sampaio CS, Atria PJ, Rueggeberg FA, et al. Effect of blue and violet light on polymerization shrinkage vectors of a CQ/TPO-containing composite. Dent Mater 2017; 33(7): 796-804.

[http://dx.doi.org/10.1016/j.dental.2017.04.010] [PMID: 28522161]

[32] Soares CJ, Bragança GF, Pereira RADS, et al. Irradiance and radiant exposures delivered by LED light-curing units used by a left and righthanded operator. Braz Dent J 2018; 29(3): 282-9.

[http://dx.doi.org/10.1590/0103-6440201802127] [PMID: 29972455]

[33] Flury S, Lussi A, Hickel R, Ilie N. Light curing through glass ceramics with a second- and a third-generation LED curing unit: Effect of curing mode on the degree of conversion of dual-curing resin cements. Clin Oral Investig 2013; 17(9): 2127-37.

[http://dx.doi.org/10.1007/s00784-013-0924-4] [PMID: 23392728]

[34] Vandewalle KS, Roberts HW, Miniotis N, Swift EJ Jr. Critical appraisal. Quartz-tungsten-halogen and light-emitting diode curing lights. J Esthet Restor Dent 2006; 18(3): 161-7.

[http://dx.doi.org/10.1111/j.1708-8240.2006.00009.x]

[PMID: $16831190]$

[35] Lima RBW, Troconis CCM, Moreno MBP, Murillo-Gómez F, De Goes MF. Depth of cure of bulk fill resin composites: A systematic review. J Esthet Restor Dent 2018; 30(6): 492-501. [http://dx.doi.org/10.1111/jerd.12394] [PMID: 30375146]

(C) 2021 Nassar and Abou Neel.

This is an open access article distributed under the terms of the Creative Commons Attribution 4.0 International Public License (CC-BY 4.0), a copy of which is available at: https://creativecommons.org/licenses/by/4.0/legalcode. This license permits unrestricted use, distribution, and reproduction in any medium, provided the original author and source are credited. 